Orthopäde $2014 \cdot 43: 413$

DOI 10.1007/s00132-013-2187-9

Online publiziert: 13. April 2014

๑) Springer-Verlag Berlin Heidelberg 2014

T. Renkawitz ${ }^{1}$ · F. von Knoch ${ }^{2}$

${ }^{1}$ Orthopädische Klinik für die Universität Regensburg, Asklepios Klinikum Bad Abbach

${ }^{2}$ Gelenkzentrum Zürich, Privatklinik Bethanien, Zürich

\title{
Update Gonarthrose
}

\section{Konservative und operative Behandlungsverfahren}

Das vorliegende Themenheft bietet gerade unter diesen mannigfaltigen $\mathrm{Ge}$ sichtspunkten ein umfassendes Update zur konservativen und gelenkerhaltend/ersetzenden Behandlung der Gonarthrose. Unser besonderer Dank gebührt den renommierten Autoren aus Deutschland, Österreich und der Schweiz, die in praxisbezogenen Übersichtsartikeln den aktuellen Wissenstand und erfolgsversprechende Therapieverfahren bei der Gonarthrose zusammengefasst haben.

Wir wünschen Ihnen viel Vergnügen bei der Lektüre dieses Hefts,

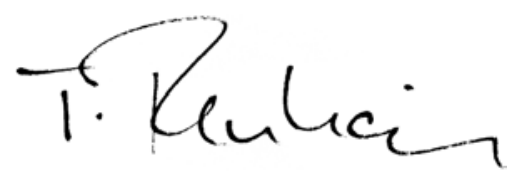

Ihr PD Dr. Tobias Renkawitz,

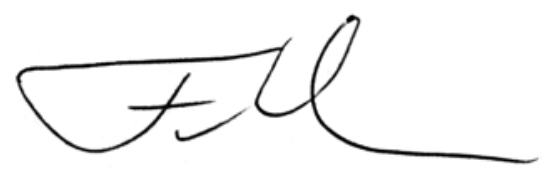

Ihr PD Dr. Fabian von Knoch

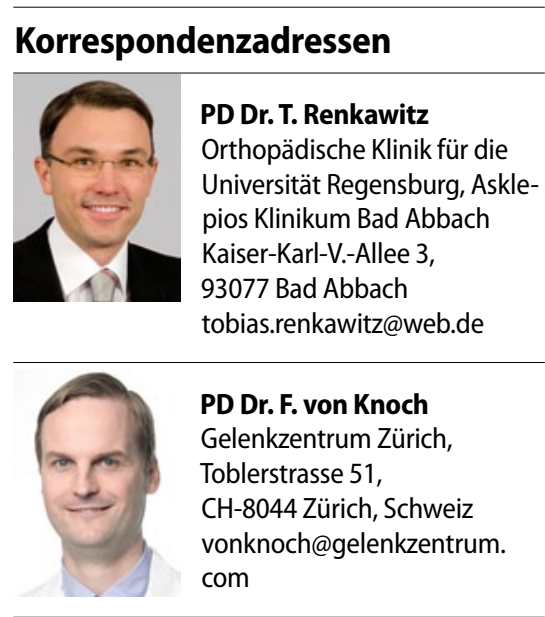

Einhaltung ethischer Richtlinien

Interessenkonflikt. T. Renkawitz gibt an, dass kein Interessenkonflikt besteht. F. von Knoch hat von Depuy Synthes Honorare für Vortrags- und Beratertätigkeiten auf dem Gebiet der unikondylären Kniearthroplastik erhalten.

Dieser Beitrag beinhaltet keine Studien an Menschen oder Tieren. auch operativ tätigen Orthopäden unab dingbar, den Überblick über erfolgreiche Versorgungsstrategien bei der Kniearthrose zu behalten.

Neue Techniken und Materialien zur operativen Versorgung der Gonarthrose versprechen ein verbessertes postoperatives Ergebnis, aber vor welchen besonderen Herausforderungen bei der Indikationsstellung und im Operationssaal steht der orthopädische Chirurg? Sind neue Technologien den konventionellen Verfahren dabei wirklich überlegen, und: Was tun, wenn unsere Patienten nach der Operation weiterhin oder plötzlich wieder Schmerzen haben? 